\title{
The Role of Synoptic Waves in the Formation and Maintenance of the Western Hemisphere Circulation Pattern
}

\author{
XIN TAN \\ School of Atmospheric Sciences, Nanjing University, Nanjing, China \\ Ming BAO \\ School of Atmospheric Sciences, Nanjing University, and China Meteorological Administration-Nanjing University \\ Joint Laboratory for Climate Prediction Studies, Nanjing, China \\ DENNIS L. HARTMANN \\ Department of Atmospheric Sciences, University of Washington, Seattle, Washington \\ PAULO CEPPI \\ Department of Meteorology, University of Reading, Reading, United Kingdom
}

(Manuscript received 9 March 2017, in final form 28 August 2017)

\begin{abstract}
Previous studies have demonstrated that the NAO, the leading mode of atmospheric low-frequency variability over the North Atlantic, could be linked to northeast Pacific climate variability via the downstream propagation of synoptic waves. In those studies, the NAO and the northeast Pacific climate variability are considered as two separate modes that explain the variance over the North Atlantic sector and the east Pacific-North American sector, respectively. A newly identified low-frequency atmospheric regime-the Western Hemisphere (WH) circulation pattern - provides a unique example of a mode of variability that accounts for variance over the whole North Atlantic-North American-North Pacific sector. The role of synoptic waves in the formation and maintenance of the WH pattern is investigated using the ECMWF reanalysis datasets. Persistent WH events are characterized by the propagation of quasi-stationary Rossby waves across the North Pacific-North American-North Atlantic regions and by associated storm-track anomalies. The eddy-induced low-frequency height anomalies maintain the anomalous low-frequency ridge over the Gulf of Alaska, which induces more equatorward propagation of synoptic waves on its downstream side. The eddy forcing favors the strengthening of the midlatitude jet and the deepening of the mid-to-high-latitude trough over the North Atlantic, whereas the deepening of the trough over eastern North America mostly arises from the quasi-stationary waves propagating from the North Pacific. A case study for the 2013/14 winter is examined to illustrate the downstream development of synoptic waves. The roles of synoptic waves in the formation and maintenance of the WH pattern and in linking the northeast Pacific ridge anomaly with the NAO are discussed.
\end{abstract}

\section{Introduction}

Previous studies have identified several extratropical large-scale atmospheric circulation patterns, which can explain the natural climate variability on time scales of months and longer. The Pacific-North American (PNA) pattern (Wallace and Gutzler 1981) and the North Atlantic Oscillation (NAO; Hurrell et al. 2003) are the two most prominent teleconnection patterns over the

Corresponding author: Ming Bao, baom@nju.edu.cn
Northern Hemisphere extratropics. Various mechanisms have been proposed to account for the growth and maintenance of the PNA: stationary Rossby wave energy dispersion from tropical heating (Hoskins and Karoly 1981), barotropic instability of the subtropical Pacific jet exit region (Simmons et al. 1983), and transient eddy forcing and feedback (Lau 1988; Branstator

Publisher's Note: This article was revised on 9 January 2018 to correct the corresponding author's affiliation. 
1992; Feldstein 2002; Orlanski 2005). The fundamental dynamical processes of the growth and maintenance of the NAO are also dominated by transient eddy fluxes (Feldstein 2003; Vallis et al. 2004; Vallis and Gerber 2008; Eichelberger and Hartmann 2007; Barnes and Hartmann 2010).

Many studies have emphasized a synoptic-scale Rossby wave breaking view of the NAO (Benedict et al. 2004; Franzke et al. 2004; Rivière and Orlanski 2007; Martius et al. 2007; Woollings et al. 2008; Strong and Magnusdottir 2008a). Benedict et al. (2004) and Franzke et al. (2004) suggested the NAO is maintained by the successive breaking of upstream synoptic-scale waves. Simulations by Rivière and Orlanski (2007) confirmed that waves coming from the eastern Pacific are crucial for determining the NAO phase. Such upstream influence was also found by Strong and Magnusdottir (2008a,b). Some of the downstream eddy propagation from the North Pacific (NP) to the North Atlantic (NA) occurs through the downstream dispersion of synoptic wave energy (i.e., the so-called downstream development process) (Chang 1993, 2001; Chang and Orlanski 1993).

The above studies demonstrated the influence of synoptic waves from the eastern Pacific on Rossby wave breaking and atmospheric circulation in the NA. Other studies suggested a connection between the NP lowfrequency flow and the NAO. Feldstein (2003) observed that for the positive NAO phase, an anomalous lowfrequency wave train propagates across the NP to the east coast of North America 4 days prior to the onset of the NAO. Observations showed the existence of a linkage between the PNA and the NAO (Pozo-Vázquez et al. 2001; Song et al. 2009; Pinto et al. 2011). It was suggested that the observed anticorrelation between PNA and NAO might be caused by the anomalous Rossby wave breaking events associated with the PNA pattern. This linkage is also manifested as a seesaw between the Aleutian and Icelandic lows in sea level pressure (SLP) fields (Honda et al. 2001). Furthermore, Woollings et al. (2008) identified dynamical precursors to wave breaking associated with the NAO including a quasi-stationary Rossby wave train stretching across North America from the Pacific. Drouard et al. (2013) identified a low-frequency ridge anomaly in the northeastern Pacific in the days prior to the maximum of the positive NAO phase both in the reanalysis and in a three-level quasigeostrophic model. The above studies indicated that synoptic waves from the eastern Pacific are likely organized by the NP lowfrequency flow and then maintain the NAO.

Besides the link between circulations over the NP and the NA, many studies on the influence of ENSO on the NA atmospheric circulation have been performed in the last decades (e.g., Pozo-Vázquez et al. 2001; Li and Lau 2012a; Drouard et al. 2015, and references therein). While the strong PNA-like response to ENSO is well documented (Horel and Wallace 1981; Trenberth et al. 1998), the response of NAO anomalies to the tropical forcing associated with ENSO is more complex and indirect. Li and Lau (2012a,b) used a 2000-yr integration of a coupled general circulation model and observations to examine the dynamical mechanism involving transient eddies for the late winter teleconnection between ENSO and the NAO. They demonstrated that anomalous downstream eddy propagation from the NP to the NA links ENSO and the NAO when focusing on the persistent flow pattern episodes associated with ENSO (Li and Lau 2012b). Similarly, Drouard et al. (2015) observed a modification of the direction of wave propagation downstream of the northeast Pacific lowfrequency anomalies associated with ENSO, which favors or prevents anticyclonic wave-breaking events in the NA depending on the ENSO phase.

In addition to teleconnection patterns like the PNA or the NAO in a specific sector, there exist hemispherescale modes such as the northern annular mode (NAM; Thompson and Wallace 2000) and the cold ocean-warm land (COWL) pattern (Wallace et al. 1996) in the Northern Hemisphere extratropics. The persistence of the NAM is mainly explained by a feedback between transient eddies and the zonal flow (Lorenz and Hartmann 2003). The COWL pattern is similar to the second EOF of mid-to-upper-tropospheric geopotential height in the Northern Hemisphere (Quadrelli and Wallace 2004). Drouard et al. (2015) provided a physical interpretation for the NAM and COWL patterns based on the role of synoptic waves and the mechanism suggested in Drouard et al. 2013. Rivière and Drouard (2015a) further demonstrated that the dynamics of the NAM at weekly time scales are linked with downstream propagation of low-frequency planetary-scale and highfrequency synoptic waves.

Recently, Bao and Wallace (2015) identified four dominant Northern Hemisphere wintertime 500-hPa flow regimes using the self-organizing maps method. One pattern is the negative polarity of the NAO, and two patterns project upon the negative and positive polarities of the PNA pattern, respectively. But the final pattern, called the Western Hemisphere (WH) pattern (M. Bao et al. 2017, unpublished manuscript, hereinafter BCHT) extends from the NP to the NA like a wave train (Fig. 1b). The WH pattern shows an anomalous ridge centered over the Gulf of Alaska and a strengthened midlatitude jet in the NA; it therefore differs from the PNA and the NAO. BCHT discussed the differences among the first three leading modes of the Northern Hemisphere 500-hPa geopotential height fields. Different 
(a) $250 \mathrm{hPa} \mathrm{Z}$

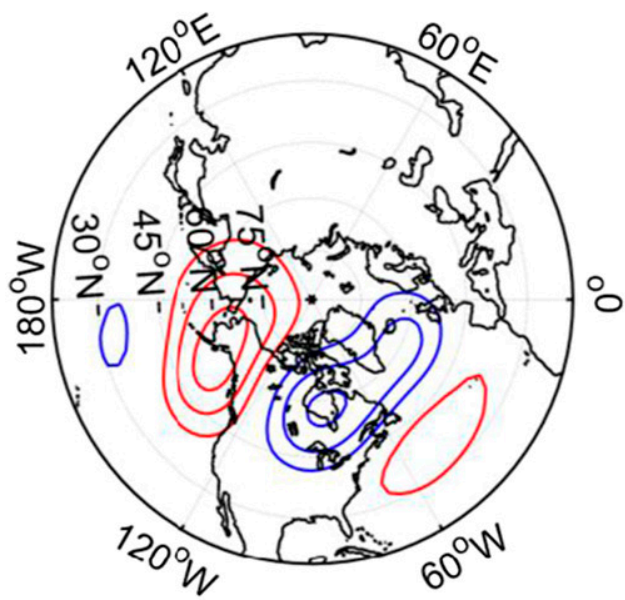

(b) $500 \mathrm{hPa} \mathrm{Z}$

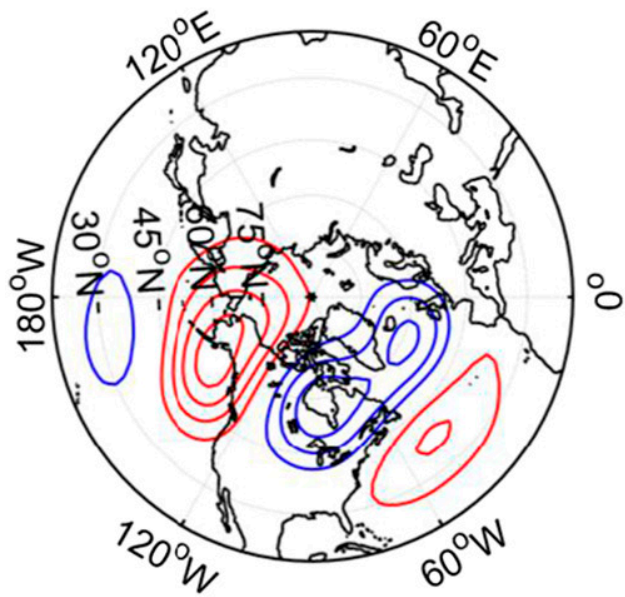

(c) $700 \mathrm{hPa} \mathrm{Z}$

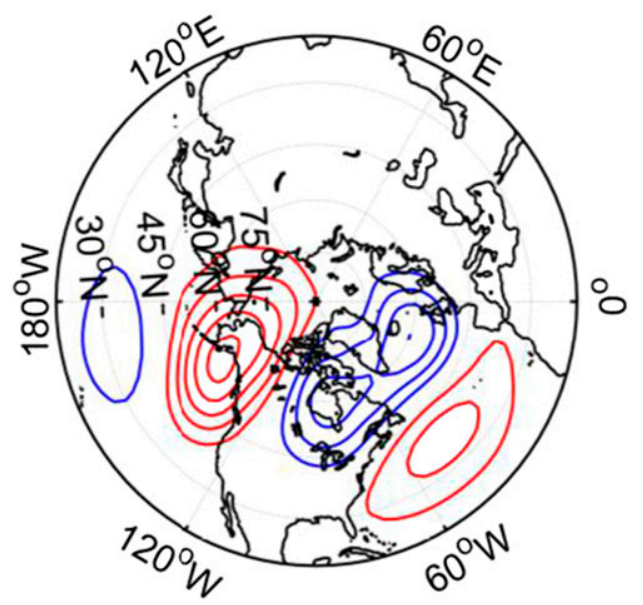

(d) $250 \mathrm{hPa} U$

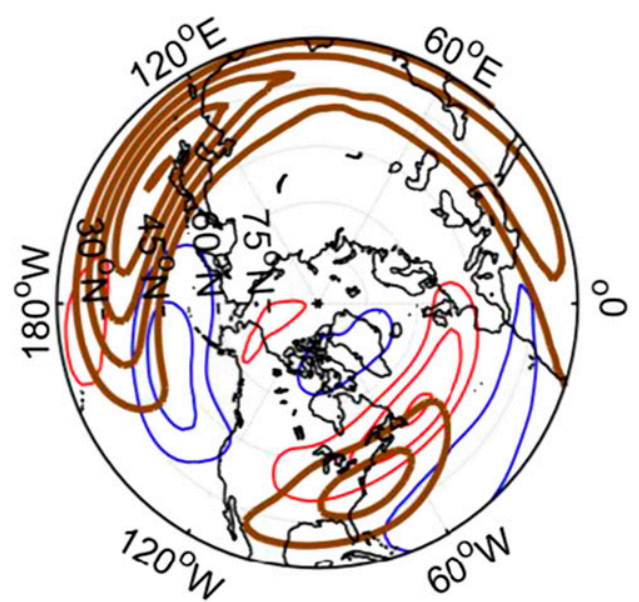

(e) $500 \mathrm{hPa} \mathrm{U}$

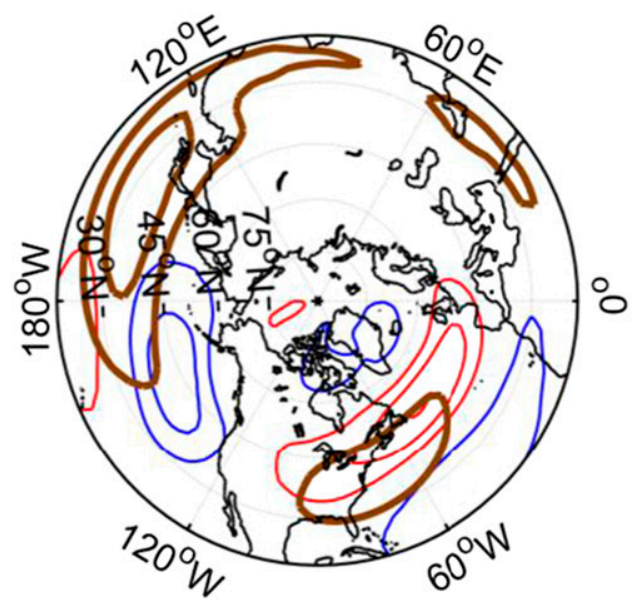

(f) $700 \mathrm{hPa} \mathrm{U}$

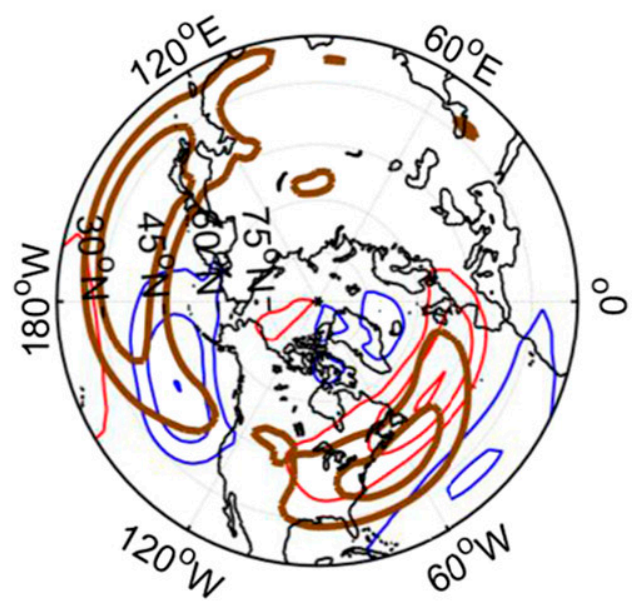

FIG. 1. Horizontal distribution of composites of the anomalous geopotential height at (a) 250, (b) 500, and (c) $700 \mathrm{hPa}$ (contour intervals: 50,30, and $20 \mathrm{~m}$, respectively) and zonal wind anomalies at (d) 250, (e) 500, and (f) $700 \mathrm{hPa}$ (contour intervals 4,3 , and $2 \mathrm{~m} \mathrm{~s}^{-1}$, respectively). The composites are averaged over the days of occurrence of the WH pattern [obtained by self-organizing maps cluster analysis, as noted in Bao and Wallace (2015)]. The brown contours in (d)-(f) denote DJF-mean climatological-mean zonal wind (contour intervals: 10,10 , and $5 \mathrm{~m} \mathrm{~s}^{-1}$ beginning at 30,20 , and $10 \mathrm{~m}$, respectively). Red (blue) contours denote positive (negative) anomalies. Zero contours are omitted. 
from the leading mode (the NAM), the WH pattern is similar to the third EOF of the Northern Hemisphere $500-\mathrm{hPa}$ geopotential height monthly fields north of $20^{\circ} \mathrm{N}$ over the regions from the NP to the NA, and the correlation between PC3 and the WH index is significant (BCHT). Thus, the WH pattern can be considered as a hemisphere-scale mode encompassing the NP, North American, and NA regions.

BCHT observed that the $250-\mathrm{hPa}$ streamfunction anomalies and stationary Rossby wave activity fluxes associated with the WH pattern indicate wave propagation from the subtropical central Pacific through North America. Tropical Pacific SST anomalies associated with the WH pattern show a prominent west Pacific warming around $150^{\circ} \mathrm{E}-180^{\circ}$ that is not related to ENSO. They used an atmospheric general circulation model and a barotropic model to demonstrate the roles of tropical west Pacific forcing and the Pacific subtropical jet in the excitation and propagation of the wave train associated with the WH pattern. They examined the low-frequency geopotential height tendency forced by the convergence of transient eddy vorticity flux associated with the WH pattern and found that extratropical eddy-mean flow feedbacks help extend the wave train eastward to the eastern Atlantic and western Europe. Given the existing work linking the growth and maintenance of low-frequency flow patterns with upstream eddy influences from the NP, the contribution of downstream eddy development from the Pacific to the Atlantic to the WH pattern needs to be investigated. In addition, the analysis of eddy-mean flow feedbacks in BCHT is based on monthly averages, providing only a crude result. In this paper, we analyze daily data from observations and define persistent $\mathrm{WH}$ events to understand the role of synoptic waves in the formation and maintenance of the $\mathrm{WH}$ pattern.

Section 2 presents details of the data and methods. Sections 3 and 4 analyze synoptic wave-mean flow interactions during persistent events associated with the WH pattern and their evolution. In section 5, we illustrate the contributions of downstream eddy development to the formation and maintenance of the WH pattern for a specific event. A summary and discussion are provided in section 6 .

\section{Data and methods}

\section{a. Observational datasets}

The observed data used in this study are based on daily mean fields from the 40-yr European Center for Medium-Range Weather Forecasts (ECMWF) Re-Analysis (ERA-40; Uppala et al. 2005) and ECMWF interim reanalysis (ERA-Interim; Dee et al. 2011) datasets. We create a continuous 59 -winter dataset by combining the ERA-40 dataset from September 1957 through December 1978 with the ERA-Interim dataset from January 1979 through March 2016 according to Bao and Wallace (2015). The combined dataset has a horizontal resolution of $2.5^{\circ} \times 2.5^{\circ}$. Anomalous fields are obtained by removing the seasonal cycle averaged over 1957-2016. Our analysis is carried out during boreal winter, defined as the 90-day (91 days in leap years) period from 1 December through 28 or 29 February. Data from November and March are used in the filtering calculation. We obtain anomalies by subtracting the daily climatological annual cycle calculated from the entire record.

\section{b. Analysis tool}

We apply a Lanczos filter to decompose the flow into high- and low-frequency components with a cutoff period of 10 days. Synoptic waves with high-pass-filtered parts are separated from low-frequency variability patterns. Similar to Nakamura and Wallace (1990), the low-passfiltered absolute value of the high-frequency geopotential height $Z_{H}$ is defined to measure the level of eddy activity on each day:

$$
Z_{H}=\overline{\left|Z^{\prime}\right|} \sin \left(45^{\circ} \mathrm{N}\right) / \sin (\text { latitude }) .
$$

Here and in the following equations, primes denote 10-day high-pass-filtered quantities and overbars indicate smoothing with a 10-day low-pass filter. Another measure of the level of eddy activity is the eddy kinetic energy (EKE):

$$
\mathrm{EKE}=\left(u^{2}+v^{\prime 2}\right) / 2 .
$$

Here $u$ and $v$ are the zonal and meridional wind components, respectively.

To illustrate the properties of transient eddies and the interaction between transient eddies and the time-mean flow, extended Eliassen-Palm vectors (E vectors) for each day are computed using the formula of Trenberth (1986):

$$
\mathbf{E}=\frac{1}{2}\left(\overline{v^{\prime 2}}-\overline{u^{\prime 2}}\right) \mathbf{i}-\overline{u^{\prime} v^{\prime}} \mathbf{j}
$$

The $\mathbf{E}$ vectors point approximately in the direction of wave energy propagation relative to the time-mean flow. Furthermore, their divergence and curl indicate eddyinduced acceleration of the local mean zonal and meridional wind, respectively.

The low-pass-filtered tendency of the 250-hPa geopotential height $d Z / d t$ is used to illustrate the respective contributions of the nonlinear interactions among the 
synoptic eddies $(\partial Z / \partial t)_{H_{-} \text {eddy }}$, low-frequency eddies $(\partial Z / \partial t)_{L_{-} \text {eddy }}$, and the interaction between quasi-stationary waves and the climatological flow $(\partial Z / \partial t)_{L_{-} C}$. The equations are similar to Nakamura et al. (1997) and Michel and Rivière (2011):

$$
\begin{aligned}
\left(\frac{\partial Z}{\partial t}\right)_{H_{-} \text {eddy }} & =\frac{f}{g} \nabla^{-2}\left[-\nabla \cdot\left(\overline{\mathbf{V}^{\prime} \zeta^{\prime}}\right)\right], \\
\left(\frac{\partial Z}{\partial t}\right)_{L_{-} \text {eddy }} & =\frac{f}{g} \nabla^{-2}\left[-\nabla \cdot\left(\overline{\mathbf{V}_{L} \zeta_{L}}\right)\right], \text { and } \\
\left(\frac{\partial Z}{\partial t}\right)_{L_{-} C} & =\frac{f}{g} \nabla^{-2}\left\{-\nabla \cdot\left[\overline{\mathbf{V}_{L}\left(\zeta_{C}+f\right)+\zeta_{L} \mathbf{V}_{C}}\right]\right\} .
\end{aligned}
$$

Here $Z$ is the geopotential height, $f$ is the Coriolis parameter, $g$ is the gravitational acceleration, $\mathbf{V}$ is the horizontal wind vector, and $\zeta$ is the relative vorticity. The subscript $C$ indicates the climatological (DJF) mean and the subscript $L$ denotes the 10-day low-pass-filtered quantities from which the climatological mean has been subtracted.

To illustrate the direction of quasi-stationary Rossby wave propagation, we use the formulation of the wave activity flux given by Takaya and Nakamura (2001):

$$
\begin{aligned}
W_{x}= & \frac{P}{2\left|\mathbf{V}_{C}\right|}\left\{u_{C}\left[\left(\frac{\partial \psi_{L}}{\partial x}\right)^{2}-\psi_{L} \frac{\partial^{2} \psi_{L}}{\partial x^{2}}\right]\right. \\
& \left.+v_{C}\left[\frac{\partial \psi_{L}}{\partial x} \frac{\partial \psi_{L}}{\partial y}-\psi_{L} \frac{\partial^{2} \psi_{L}}{\partial x \partial y}\right]\right\} \text { and } \\
W_{y}= & \frac{P}{2\left|\mathbf{V}_{C}\right|}\left\{u_{C}\left[\left(\frac{\partial \psi_{L}}{\partial x} \frac{\partial \psi_{L}}{\partial y}\right)-\psi_{L} \frac{\partial^{2} \psi_{L}}{\partial x \partial y}\right]\right. \\
& \left.+v_{C}\left[\left(\frac{\partial \psi_{L}}{\partial y}\right)^{2}-\psi_{L} \frac{\partial^{2} \psi_{L}}{\partial y^{2}}\right]\right\} .
\end{aligned}
$$

Here $W_{x}$ and $W_{y}$ are the zonal and meridional components of the wave-activity flux, respectively, $\psi$ is the streamfunction, $P=$ (pressure $/ 1000 \mathrm{hPa})$, and $\left|\mathbf{V}_{C}\right|^{2}=$ $u_{C}^{2}+v_{C}^{2}$.

A Student's $t$ test at the $95 \%$ confidence level is applied to the composite and regression analyses to assess statistical significance. Except where otherwise stated, the geopotential height anomalies in the following sections represent low-frequency anomalies.

\section{c. Definition of persistent events}

To characterize the flow variability associated with the WH pattern, a daily time series is obtained by calculating the spatial (area-weighted) regression coefficients of the 10-day low-pass-filtered $500-\mathrm{hPa}$ geopotential height anomalies poleward of $20^{\circ} \mathrm{N}$ on the
WH pattern. The daily values of the coefficients are normalized by the standard deviation of the entire time series to obtain the WH pattern index (WHI). A persistent WH event is defined to occur when the standardized daily WHI exceeds 0.7 for at least 12 consecutive days with the peak value exceeding 1.5. The onset (decay) day is defined as the first (last) day of a persistent event.

\section{Synoptic wave-mean flow interaction during persistent WH events}

BCHT have described the $\mathrm{WH}$ pattern as a wave train extending from the NP to the NA, along with an anomalous ridge centered over the Gulf of Alaska and a trough extending from central North America through the NA in the middle and high latitudes (Fig. 1b). Based on the occurrence days of the WH pattern identified from the 10-day low-pass-filtered 500-hPa geopotential height field based on the method of self-organizing maps (Bao and Wallace 2015), Fig. 1 shows the composite geopotential height anomalies (left panels) and zonal wind anomalies (right panels) associated with the $\mathrm{WH}$ pattern on different isobaric surfaces. The similar spatial structures of the anomalous height in the upper, middle, and lower troposphere indicate a significant equivalent barotropic component of the WH pattern. Consequently, our dynamical diagnostics will focus on the upper troposphere where the strongest eddy-mean flow interactions occur in the middle and high latitudes. The zonal wind anomalies associated with the WH pattern at different levels also show some barotropicity. At each level, the midlatitude jet shifts poleward over the central and eastern NP, whereas it is strengthened and slightly poleward shifted over the central and eastern NA with weaker zonal wind on the jet flanks. The lowertropospheric jet over the NA is similar to the "central" jet proposed by Woollings et al. (2010). The features of the height and zonal wind anomalies in Fig. 1 suggest that the WH pattern is visibly distinct from either a negative phase of the PNA or a positive phase of the NAO.

After calculating the WHI and defining the persistent WH events, we obtain $33 \mathrm{WH}$ events. Figure 2 shows the WH event distribution during the winter seasons of 1957-2016. The solid lines denote the days belonging to the 33 events. The average duration of each event is around 18 days. Figure 3 shows the composites of the 10-day low-pass-filtered height anomalies and $Z_{H}$ (Fig. 3a), and $d Z / d t$ anomalies and $\mathbf{E}$ vectors (Fig. 3b) at $250 \mathrm{hPa}$ averaged over all days in the 33 persistent WH events. The horizontal distribution of the lowfrequency height anomalies is very close to that of composite 250 -hPa height anomalies over all occurrence days 


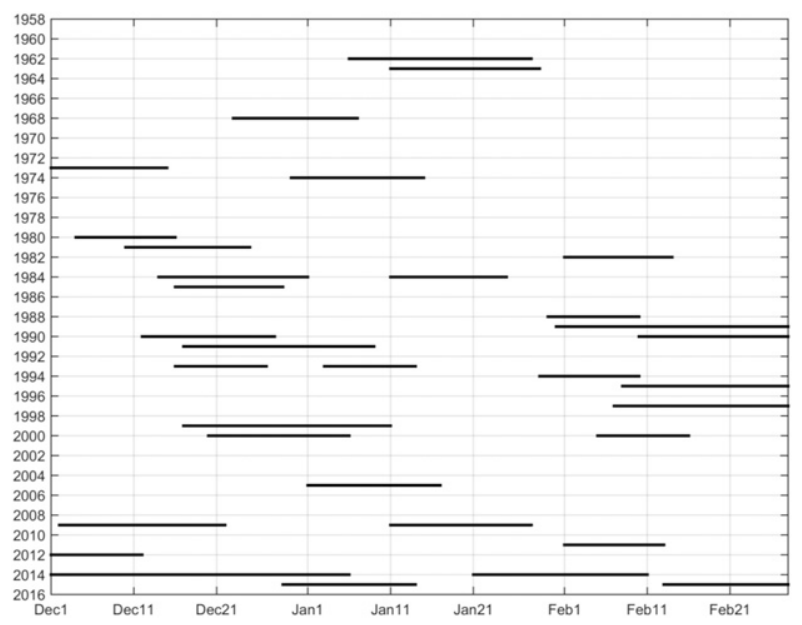

FIG. 2. Distributions of persistent WH events between the 1957/ 58 and 2015/16 winters. The solid lines denote the days belonging to persistent $\mathrm{WH}$ events. The year label applied to each winter corresponds to January.

of the WH pattern (Fig. 1a), although the anomalies associated with persistent events are more positive over southwestern Europe. The Pacific storm tracks are less active to the south of the anomalous high, whereas positive storm-track anomalies appear to the north of the anomalous high and in the Pacific subtropics. In eastern North America and the NA, the enhanced (suppressed) eddy activity occurs to the south (north) of the anomalous low, reflecting the strengthening and slight poleward shift of the Atlantic storm track.

The composite of $(\partial Z / \partial t)_{H_{-} \text {eddy }}$ anomalies shown in Fig. $3 \mathrm{~b}$ indicates that the eddy-induced height tendency reinforces the low-frequency height anomalies over the $\mathrm{NP}$ and the NA. Although the negative low-frequency height anomalies do not match the $(\partial Z / \partial t)_{H_{-} \text {eddy }}$ and $(\partial Z / \partial t)_{L_{-} \text {eddy }}$ anomalies over North America, the interaction between low-frequency waves and the climatological flow strengthens the trough over North America (Fig. 3d). In Fig. 3c, the height tendency acts to strengthen the trough over the northern part of the NA and weaken the trough over North America. Comparing the results of Figs. 3b, 3c, and 3d, we conclude that the trough over the NA is maintained mainly by the nonlinear interaction of synoptic eddies, while the trough over North America is maintained by the interaction between low-frequency waves and the climatological flow. Hence, two different dynamical mechanisms maintain the troughs over North America and the NA. We will show that the negative low-frequency height anomalies over North America result from the propagation of quasi-stationary Rossby waves originating from the NP in the next section. The $\mathbf{E}$ vectors show synoptic waves propagating poleward and equatorward upstream and downstream of the ridge anomaly in the northeastern Pacific, respectively. The equatorward propagation of synoptic waves over North America and the NA and the divergence of $\mathbf{E}$ vectors are indicative of eastward wind acceleration. The synoptic wave propagation during the $\mathrm{WH}$ events shows similar characteristics to the daily mean composite for the positive NAO phase described in Drouard et al. (2015, their Fig. 2c).

In spite of these similarities, the hemispheric-scale WH pattern extending from the NP to the NA is distinguished from the linkage between the eastern Pacific ridge anomaly and the positive NAO. Compared with the NAO-related anomalies (Fig. $2 \mathrm{c}$ in Drouard et al. 2015), the NP ridge anomaly associated with the WH pattern is shifted northeastward and is centered over the Gulf of Alaska. The different location of the anomalous Pacific ridges can bring different influences on downstream circulation structures. The ridge anomaly over the Gulf of Alaska favors the formation of the WH pattern by specific dynamical processes, such as the propagation of anomalous stationary waves and downstream eddy development that will be discussed in the following sections.

\section{Composites of the evolution of persistent WH events}

The propagation of stationary Rossby waves is an essential mechanism for understanding the formation and maintenance of large-scale low-frequency patterns. To depict the stationary Rossby wave propagation during the different stages of WH events, Fig. 4 shows the lag composite map of the 250 -hPa wave activity flux and the 250-hPa low-pass-filtered height anomalies. Day 0 denotes the day with the highest WHI of a WH event. On day -9 , the stationary waves propagating from the eastern Pacific to North America induce a ridge anomaly over the Gulf of Alaska, but have not yet produced downstream height anomalies. The trough anomaly centered over the tip of southern Greenland could be induced by eddy-mean flow interaction over the NA, similar to the positive NAO case. From day -6 to day 0 , the stationary waves intensify and the subtropical low and midlatitude ridge anomaly in the NP strengthens. The wave train deepens the trough anomaly over eastern North America and the subtropical high grows over the NA until the WH pattern reaches its peak. However, the wave activity flux shows that the anomalous stationary wave propagation cannot fully account for the dipole pattern in the central and eastern Atlantic. After day 0 , the declining upstream stationary wave propagation accompanies the weakening ridge anomaly over the Gulf of Alaska, but the stationary waves over the 

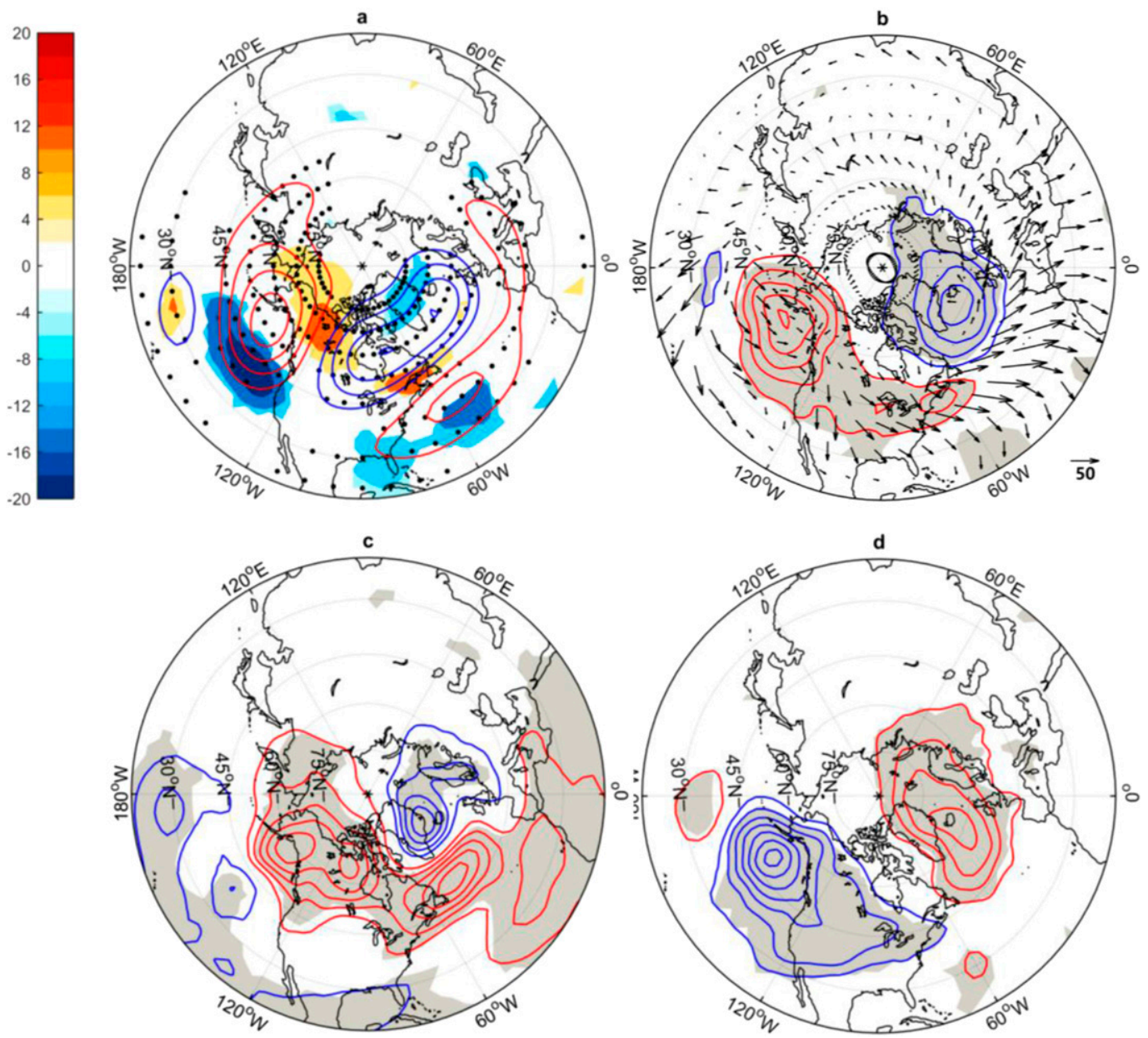

FIG. 3. Horizontal distribution of composites of the (a) anomalous 250-hPa low-frequency geopotential height (contours; interval: $50 \mathrm{~m}$ ) and anomalous $250-\mathrm{hPa} Z_{H}$ (shading only for significant anomalies; see scale bar at left side; m), (b) $250-\mathrm{hPa}(\partial Z / \partial t)_{H_{-} \text {eddy }}$ (contours; interval: $10 \mathrm{~m}$ day $^{-1}$ ) anomalies and $\mathbf{E}$ vectors (arrows), (c) $250-\mathrm{hPa}(\partial Z / \partial t)_{L_{-} \text {eddy }}$ (contours; interval: $20 \mathrm{~m} \mathrm{day}^{-1}$ ), and (d) $250-\mathrm{hPa}(\partial Z / \partial t)_{L_{-} C}$ (contours; interval: $20 \mathrm{~m} \mathrm{day}^{-1}$ ). The composites are averaged over all days in the persistent WH events. Red (blue) contours denote positive (negative) anomalous values. The dots in (a) [shading in (b)-(d)] indicate that the height anomalies $(d Z / d t$ anomalies) there are significant. Zero contours are omitted. Scaling of the arrows in (b) is given at the bottom right $\left(\mathrm{m}^{2} \mathrm{~s}^{-2}\right)$.

NA strengthen and propagate eastward and northward to Europe. Overall, the composite of wave-activity fluxes based on the WH events is consistent with the monthly composites of the WH pattern in BCHT.

Figure 5 shows the lag composite map of the $250-\mathrm{hPa}$ $Z_{H}$ and $\mathbf{E}$ vectors. The transient eddies are gradually reinforced over eastern North America and the midlatitude NA from day -9 to day -3 . This means that the anomalous transient eddies can strengthen the midlatitude Atlantic jet through eddy-mean flow feedback. The triple structure of the $Z_{H}$ anomalies over the NA becomes more evident after day -3 , which coincides with the dipole pattern of the low-frequency height anomalies in Fig. 4. Although there are negative $Z_{H}$ anomalies over southern North America accompanying the strengthened transient eddies over Alaska-which would favor a low-frequency anomalous ridge over North America at day -3 and day 0 by local eddy-mean flow feedback (cf. contours in Fig. 3b) - the formation of the observed trough anomaly over North America is obviously due to the contribution of the stationary Rossby wave propagation (Fig. 4; days -3 and 0 ). The strong $\mathbf{E}$ vectors are oriented equatorward over North America, especially between days -9 and -6 , and extend to the midlatitude NA. The results indicate that synoptic waves with anticyclonic tilt propagate equatorward from the upstream NP ridge until they reach the NA. After day 0, despite keeping an equatorward 

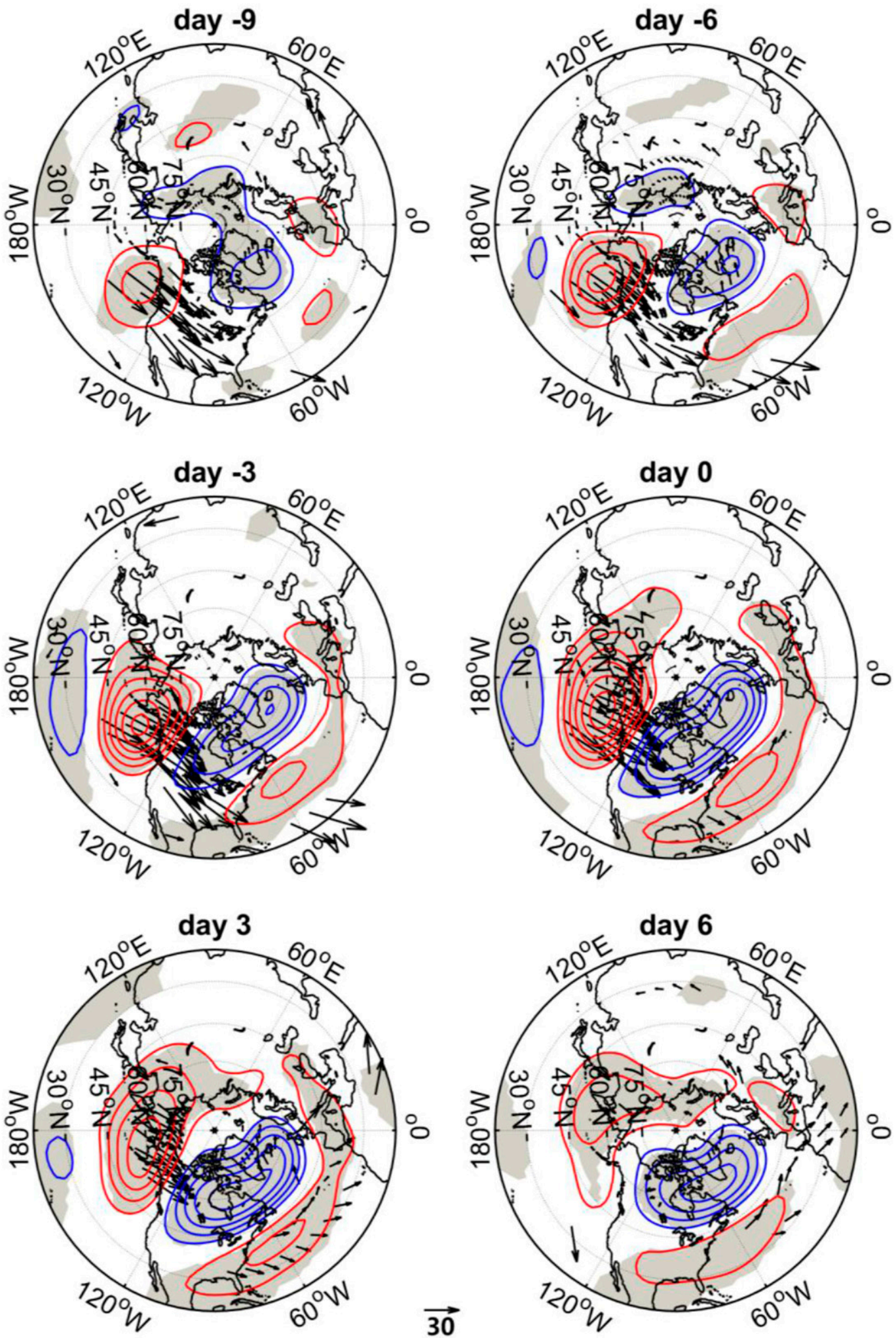

FIG. 4. Daily composites of the 250-hPa low-frequency geopotential height anomalies (contours; interval: $50 \mathrm{~m}$ ) and wave-activity flux (arrows) for lag days of all WH events. Red (blue) contours denote positive (negative) values. Zero contours are omitted. The arrows only show the significant wave-activity flux. Shading indicates that the lowfrequency height anomalies are significant. Day 0 corresponds to the day with the highest WHI of each WH event. Scaling of the arrows is given at the bottom $\left(\mathrm{m}^{2} \mathrm{~s}^{-2}\right)$. 

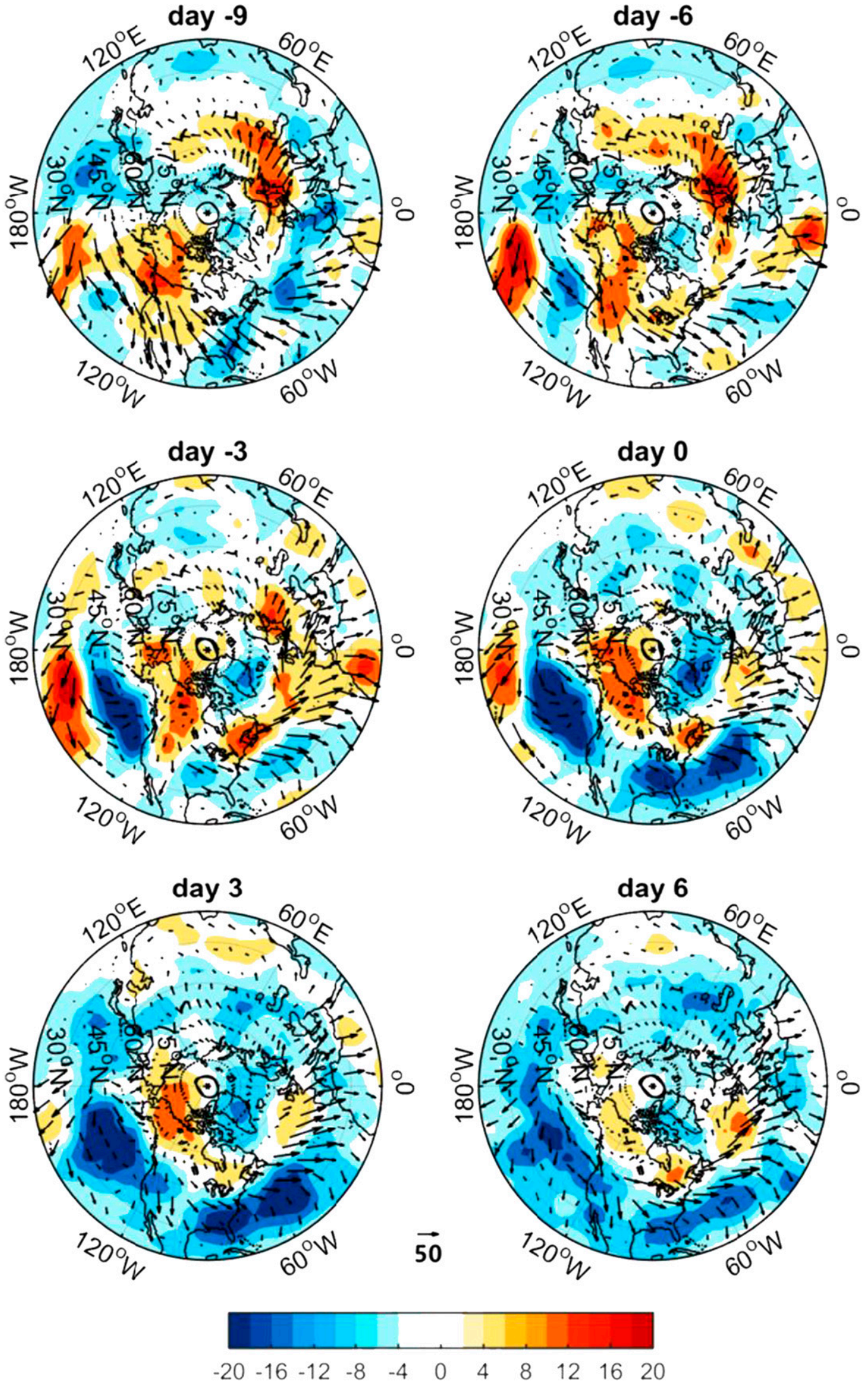

FIG. 5. As in Fig. 4, but for the 250-hPa $Z_{H}$ anomalies (shading; $\mathrm{m}$ ) and $\mathbf{E}$ vectors (arrows; $\mathrm{m}^{2} \mathrm{~s}^{-2}$ ). 
orientation, the $\mathbf{E}$ vectors over the eastern Pacific and North America weaken clearly; however, they remain roughly unchanged over the NA. The characteristics of E vectors associated with the WH pattern demonstrate the significant role of downstream eddy development in the formation and maintenance of the $\mathrm{WH}$ pattern.

As a transition zone between the NP and NA, the response over the North American continent can play an important role in linking the circulation anomalies between the NP and the NA. Li and Lau (2012a,b) suggested that if the storm-track variability over North America were removed, ENSO would have almost no impact on the NAO. Testing the influence of the lowfrequency North American anomaly on the linkage between PNA and NAO, Drouard et al. (2015) proposed that the deep anomalies over North America are able to reverse the effect of the northeast Pacific anomalies and contribute to same-signed PNA and NAO anomalies (like the COWL pattern), contrary to the NAM (which projects negatively on the PNA and positively on the $\mathrm{NAO}$ ). As for the WH pattern, although there is a single anomalous low extending from eastern North America to the NA, the local anomalies over these two areas are maintained by different mechanisms. Combining the results above, during a WH event the stationary Rossby wave propagation is more important than synoptic wave forcing to maintain the negative height anomalies over North America in the earlier stages, although the transient eddies could weaken this trough by eddy-mean flow feedback. By contrast, for the low-frequency signals over the NA, there is no obvious propagation of stationary Rossby waves, and hence eddy-mean flow feedback must be the main mechanism that maintains the anomalous low.

\section{Contributions from downstream eddy development}

One-point lag-correlation maps have been widely used to study the evolution of waves and flow patterns. To reveal the downstream development of synoptic wave trains, $\mathrm{Li}$ and Lau (2012b) analyzed one-point lagged regression patterns of unfiltered 250-hPa meridional wind anomalies based on the episodes with persistent flow patterns associated with ENSO. Their results indicated strong downstream development of wave packets during the persistent flow pattern events and offered insight into the eddy processes responsible for the ENSO-NAO relationships. Drouard et al. (2015) performed the same diagnosis on the positive and negative NAM phases. They concluded that for different NAM phases more statistically significant differences result from the orientation of wave propagation rather than the intensity and latitude.
Figure 6 shows the lagged regression maps of 10-day high-pass-filtered $250-\mathrm{hPa}$ meridional velocity anomalies for lags of $-1,0,+1,+2,+3$, and +4 days during the periods with persistent $\mathrm{WH}$ events. Considering the typical wavelength of synoptic waves, we choose two reference points located in the upstream active region of synoptic waves (active region seen in Fig. 3a) to represent two opposite phases of synoptic wave at slightly different latitudes: one is at $55^{\circ} \mathrm{N}, 120^{\circ} \mathrm{W}$ and the other at $60^{\circ} \mathrm{N}, 150^{\circ} \mathrm{W}$. Similar to $\mathrm{Li}$ and Lau (2012b, their Fig. 7), since the upstream wave packet originates from a higher latitude due to the ridge over the Gulf of Alaska, it refracts equatorward with a pronounced anticyclonic tilt when crossing North America. This is consistent with the more equatorward $\mathbf{E}$ vectors over North America, as shown in Fig. 3b. The lagged regressions for the two reference points both indicate the synoptic waves propagating southeastward from the NP and North America to the NA. Contrasting the two reference points, the synoptic waves originating from the more southeastward point (Fig. 6, left) propagate farther to the east Atlantic and are characterized with higher wave amplitude over North America and the NA compared to the other (Fig. 6, right). As reviewed in the introduction, the downstream eddy development process contributes to the maintenance of the NAO. For the WH pattern, the upstream synoptic wave trains associated with the anomalous Alaska ridge similarly contribute to the formation and maintenance of the low-frequency circulation anomalies over the NA, but with different routes (owing to different locations of upstream lowfrequency ridge/trough).

Rivière and Drouard (2015b) suggested that the winter of 2013/14 was dominated by a positive NAO. However, NOAA/Climate Prediction Center data for December-February of 2013/14 reports standardized NAO monthly index values of $0.95,0.29$, and 1.34 , respectively. Although these values are positive, they indicate that the 2013/14 winter was not characterized by a strong positive NAO. On the other hand, the WH pattern helps to interpret the flow pattern during the exceptional winter of 2013/14 (Hartmann 2015; Bao and Wallace 2015; see Fig. 1c in BCHT). As shown in Fig. 2, two persistent WH events including an extra-long one appear in the winter of 2013/14. Therefore, we choose this winter as a case study for the contributions of eddy downstream development to the WH pattern.

Figure 7 shows the longitude-time cross section of the 250-hPa anomalous EKE and 10-day high- and lowpass-filtered anomalous meridional winds for the 2013/ 14 winter. The value at each longitude in Fig. 7a is the EKE maximum of EKE anomalies averaged over overlapping $10^{\circ}$ latitude bands. The values of meridional 

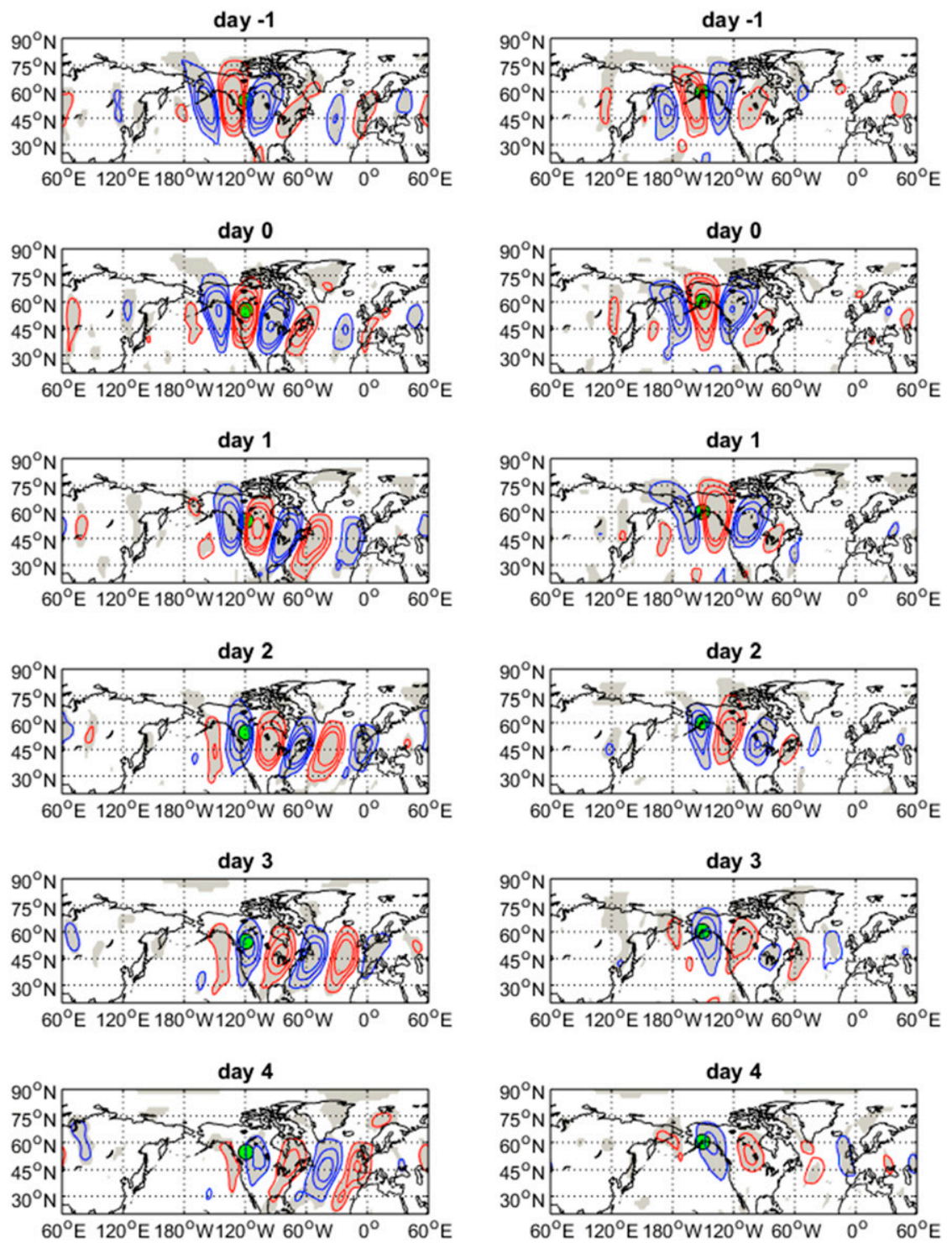

FIG. 6. One-point lagged regression maps of 250-hPa 10-day high-pass-filtered meridional velocity anomalies during the WH events. The reference time series is $250-\mathrm{hPa} 10$-day highpass-filtered meridional velocity on day 0 at (left) $55^{\circ} \mathrm{N}, 120^{\circ} \mathrm{W}$ and (right) $60^{\circ} \mathrm{N}, 150^{\circ} \mathrm{W}$ ), as indicated by the green dot in each figure. The contours of the regression coefficients are $\pm 1, \pm 2$, $\pm 3, \pm 6$, and $\pm 9 \mathrm{~m} \mathrm{~s}^{-1}$. Red (blue) contours denote positive (negative) values. Zero contours are omitted. Shading indicates significant regression coefficients beyond the $95 \%$ confidence level based on the $t$ test.

velocity in Figs. $7 \mathrm{~b}$ and $7 \mathrm{c}$ are averaged over $35^{\circ}-65^{\circ} \mathrm{N}$. During the first WH event (from 1 December to 6 January), there are frequent downstream development events of synoptic waves from the NP $\left(180^{\circ}-120^{\circ} \mathrm{W}\right)$ to the NA $\left(60^{\circ} \mathrm{W}-0^{\circ}\right)$. By contrast, during the second $\mathrm{WH}$ event (from 21 January to 11 February), the stationary Rossby wave propagation from the NP to the NA is obvious from 12 to 22 January without evident downstream propagation of synoptic waves (Figs. $7 b, c$ ). Therefore, for the 2013/14 case, it is clear that the strong eddy activity over the NA was influenced by the upstream storm track over the NP and Alaska during the first WH event. Downstream eddy development favors the formation of a trough anomaly over the NA, enhancing the persistence of this extra-long WH event. Given the absence of downstream eddy development during the second moderate WH event, we believe that downstream eddy development may not be necessary for some moderate or weak WH events, since stationary wave propagation and local eddy-mean flow interaction 


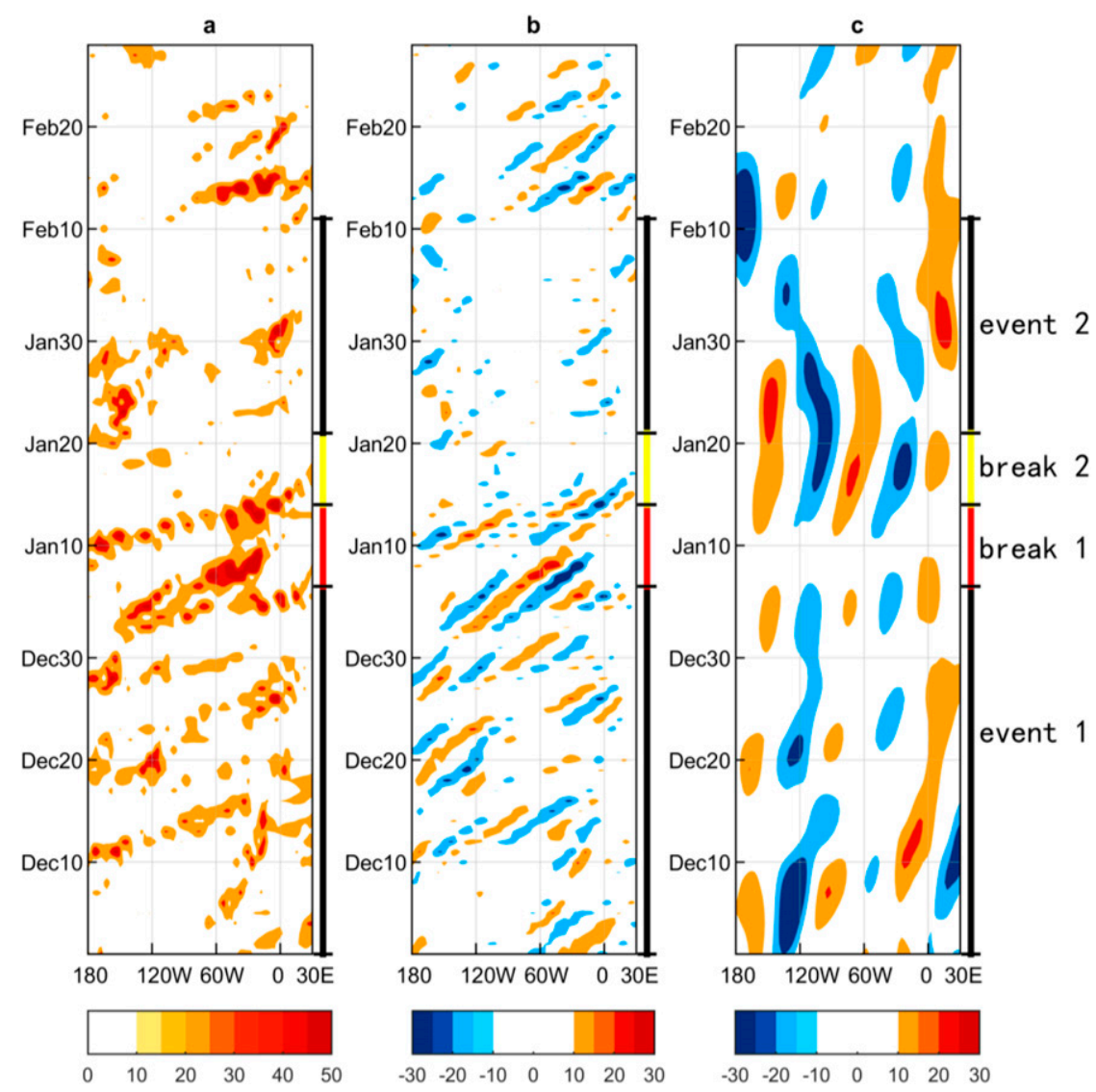

FIG. 7. Longitude-time cross sections of (a) 250-hPa anomalous EKE, (b) 10-day high-passfiltered meridional velocity anomalies, and (c) 10-day low-pass-filtered meridional velocity anomalies. The value at each longitude in (a) is the maximum of EKE anomalies averaged over overlapping $10^{\circ}$ latitude bands poleward of $20^{\circ} \mathrm{N}$. The values of meridional velocity anomalies in (b) and (c) are averaged over $35^{\circ}-65^{\circ} \mathrm{N}$. The diagrams are for the entire winter of $2013 / 14$. Definitions of events 1 and 2 and breaks 1 and 2 are provided in the text.

over the NA are able to contribute to the formation and maintenance of the WH pattern as well.

Between the two events, we have defined two stages called break 1 (7-13 January) and break 2 (14-20 January) marked in Fig. 7. Break 1 is characterized by intense synoptic wave propagation from the NP to the NA, whereas break 2 features a strong low-frequency wave train. Figure 8 shows $250-\mathrm{hPa}$ geopotential height anomalies and $\mathbf{E}$ vectors for the four stages (event 1, break 1, break 2, and event 2) in the winter of 2013/14. For event 1 (Fig. 8a), not only the quasi-stationary waves but also the $\mathbf{E}$ vectors are similar to the composites of the WH events in Fig. 3. Compared to the composite results in Fig. 3, the low-frequency ridge over the Gulf of Alaska has weakened during the break-1 stage, and the midlatitude synoptic waves over North America (near $50^{\circ} \mathrm{N}$ ) propagate eastward and slightly poleward due to the weakening of the upstream ridge (Fig. 8b). During the break-2 stage (Fig. 8c), the quasi-stationary Rossby wave propagation appears as a zonal wave train, which is distinct from the WH events. The break of the two events is due to changes in the propagation of both quasi-stationary and synoptic waves. As for event 2 (Fig. 8d), the $\mathbf{E}$ vectors do not show evident synoptic wave propagation from the NP. It is possible that the poleward shifted ridge over Alaska does not favor eddy downstream development. The NA sector of the WH pattern for event 2 was maintained by local eddy-mean flow feedback, in accordance with the local eddy activities over the NA in Fig. 7b. The lack of eddy downstream development could impact the persistence of the WH pattern.

\section{Summary and discussion}

The role of synoptic waves in forming and maintaining the WH pattern is investigated in this study using the ECMWF daily reanalysis datasets. While the WH 

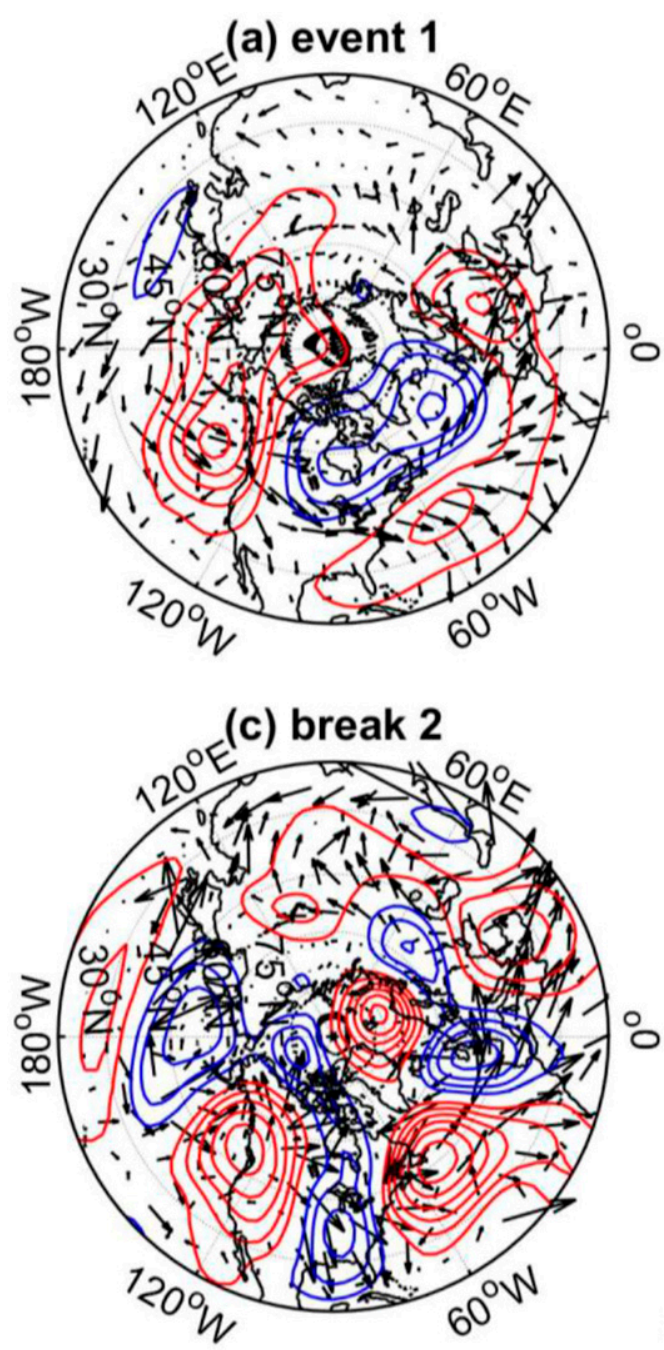

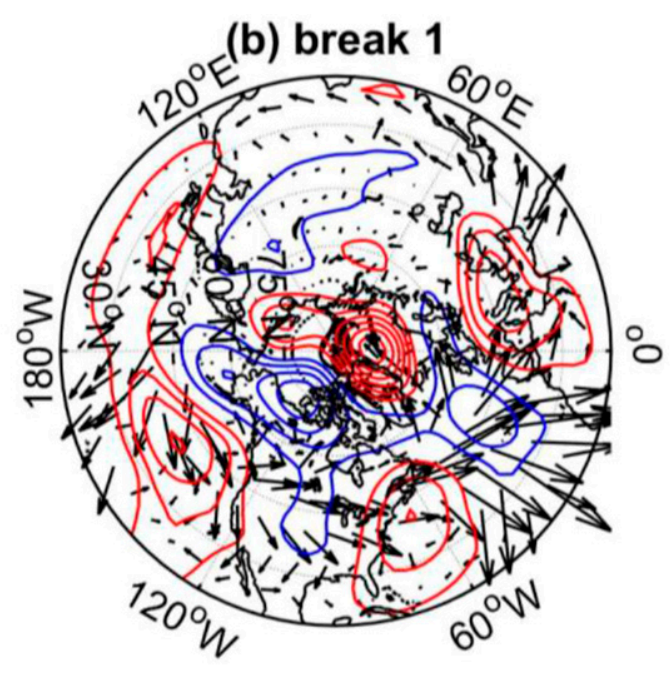

(d) event 2

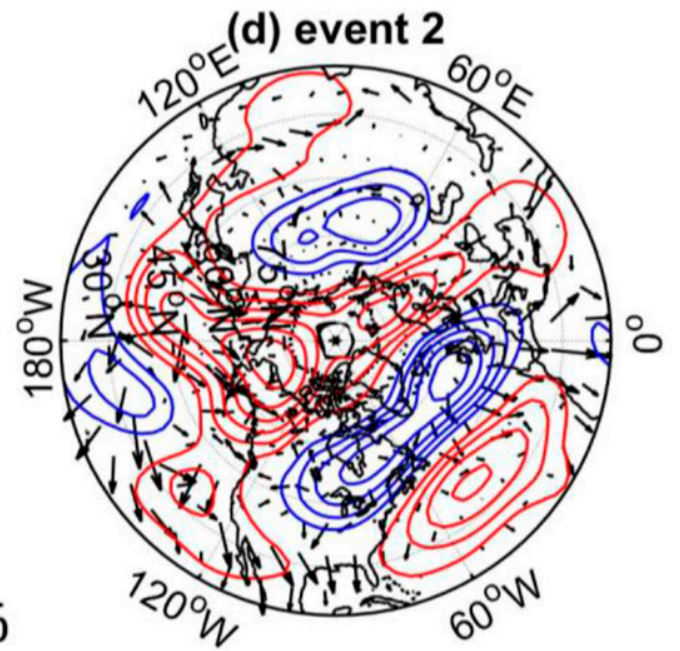

FIG. 8. Horizontal distribution of 250-hPa low-frequency geopotential height anomalies (contours; interval: $50 \mathrm{~m}$ ) and $\mathbf{E}$ vectors (arrows) for four stages (shown in Fig. 7) during the winter of 2013/14. Red (blue) contours denote positive (negative) anomalous values. Zero contours are omitted. Scaling of the arrows is given at the bottom $\left(\mathrm{m}^{2} \mathrm{~s}^{-2}\right)$.

pattern appears as a stationary Rossby wave train propagating from the NP to the NA, our results indicate that the propagation of quasi-stationary Rossby waves alone cannot fully account for the formation and maintenance of the WH pattern, particularly for the trough anomaly in the NA. A composite of persistent WH events shows that the ridge anomaly over the Gulf of Alaska is not only maintained by eddy-mean flow feedback but also favors a more active storm track over northwestern North America and causes anomalous equatorward synoptic wave propagation on the downstream side. Lagged regression analysis reveals downstream development of synoptic wave packets during WH episodes. When these waves with a southwestnortheast tilt enter the NA, they interact with the anomalous quasi-stationary waves to promote eddymean flow feedback in the NA. These processes help extend the trough anomaly eastward into the NA and favor the persistence of the WH pattern.

We examine the 2013/14 winter as a case study of the WH pattern. Recent studies on 2013/14 winter focused on the seasonal mean circulation anomalies and the tropical Pacific sea surface temperature anomalies (e.g., Hartmann 2015; see also the review in BCHT), while very few have noticed the role of synoptic waves (Davies 2015; Rivière and Drouard 2015b). An anomalously persistent WH event in December 2013-early January 2014 confirmed the contributions of downstream eddy development to the maintenance of the WH pattern. Frequent wave packets originated from the NP and 
propagated across North America. In contrast, another moderate persistent WH event in the late January-early February shows no evident upstream synoptic waves, the formation and maintenance of the $\mathrm{WH}$ pattern being dominated by stationary waves and local downstream eddy-mean flow feedbacks. The break between the two events is due to changes in the propagation of both quasi-stationary and synoptic waves. These results indicate that both stationary and synoptic waves are important for the WH pattern and suggest eddy downstream development process could be more important for the persistence of the WH pattern.

The role of synoptic wave downstream development in our study is in accordance with the results of $\mathrm{Li}$ and Lau (2012a,b) and Drouard et al. (2013, 2015). Different from their studies on the link between the NAO and NP climate variability, our study focuses on a newly identified low-frequency flow pattern of which the NP ridge anomaly itself is an element. For the hemispheric-scale NAM pattern, evidence of stationary wave propagation from the NP to the NA cannot be found (Drouard et al. 2015). Rivière and Drouard (2015a) showed that for the rapid fluctuations of the NAM events, the propagation of low-frequency wave trains explains the initiation of the NAM events while synoptic waves play a major role during the last onset week. From this perspective, the WH pattern provides a unique example for the climate influence of the NP on North America and the NA through both stationary and synoptic waves, with equivalent importance but playing different roles.

Our study suggests that the impact of the WH pattern on European weather mostly relies on the storm-track anomaly in the NA, which can be affected by the upstream storm track modulated by the NP low-frequency ridge anomaly. A low-frequency wave source produced by the eddy-mean flow interaction in the NA triggers a quasi-stationary Rossby wave propagating northeastward toward Europe, where a weak ridge anomaly thus forms.

The case of the 2013/14 winter provides a good example of the relevance of our results for European climate. The 2013/14 winter was the stormiest over the British Isles on record, and the heavy precipitation associated with the numerous cyclones led to widespread flood events over the region (e.g., Huntingford et al. 2014; Matthews et al. 2014; Priestley et al. 2017b). The large-scale conditions were characterized by a very intense, quasi-stationary polar jet stream over the Atlantic that guided a large number of storms toward the British Isles (Priestley et al. 2017a). While there has been some discussion on the remote reasons for this setup [e.g., the role of the tropical Pacific in Huntingford et al. (2014) and Wild et al. (2015)], no clear evidence has yet been provided. The WH events during the 2013/14 winter discussed here link the tropical west Pacific to the largescale conditions over the NA and western Europe (BCHT). Therefore, our study suggests that more attention should be paid to the remote origin of the circulation anomalies in the NA independent of the NAO (Ciasto et al. 2016).

Acknowledgments. We thank Gwendal Rivière and two anonymous reviewers for their insightful comments and constructive suggestions, which greatly improved the manuscript. XT and MB were supported by the National Natural Science Foundation of China (Grants 41675048, 41275054, and 41330420). DLH was supported by the National Science Foundation under Grant AGS-0960497, and PC received support from the ERC Advanced Grant "ACRCC” (Grant 339390).

\section{REFERENCES}

Bao, M., and J. M. Wallace, 2015: Cluster analysis of Northern Hemisphere wintertime $500-\mathrm{hPa}$ flow regimes during 1920-2014. J. Atmos. Sci., 72, 3597-3608, doi:10.1175/ JAS-D-15-0001.1.

Barnes, E. A., and D. L. Hartmann, 2010: Dynamical feedbacks and the persistence of the NAO. J. Atmos. Sci., 67, 851-865, doi:10.1175/2009JAS3193.1.

Benedict, J. J., S. Lee, and S. B. Feldstein, 2004: Synoptic view of the North Atlantic Oscillation. J. Atmos. Sci., 61, 121-144, doi:10.1175/1520-0469(2004)061<0121:SVOTNA $>2.0$. CO;2.

Branstator, G., 1992: The maintenance of low-frequency atmospheric anomalies. J. Atmos. Sci., 49, 1924-1946, doi:10.1175/ 1520-0469(1992)049<1924:TMOLFA > 2.0.CO;2.

Chang, E. K. M., 1993: Downstream development of baroclinic waves as inferred from regression analysis. J. Atmos. Sci., 50, 2038-2053, doi:10.1175/1520-0469(1993)050<2038: DDOBWA $>2.0 . \mathrm{CO} ; 2$.

- 2001: The structure of baroclinic wave packets. J. Atmos. Sci., 58, 1694-1713, doi:10.1175/1520-0469(2001)058<1694: TSOBWP $>2.0 . \mathrm{CO} ; 2$.

_ , and I. Orlanski, 1993: On the dynamics of a storm track. J. Atmos. Sci., 50, 999-1015, doi:10.1175/1520-0469(1993)050<0999: OTDOAS $>2.0 . \mathrm{CO} ; 2$.

Ciasto, L. M., C. Li, J. J. Wettstein, and N. G. Kvamstø, 2016: North Atlantic storm-track sensitivity to projected sea surface temperature: Local versus remote influences. J. Climate, 29, 69736991, doi:10.1175/JCLI-D-15-0860.1.

Davies, H. C., 2015: Weather chains during the 2013/2014 winter and their significance for seasonal prediction. Nat. Geosci., $\mathbf{8}$, 833-837, doi:10.1038/ngeo2561.

Dee, D. P., and Coauthors, 2011: The ERA-Interim reanalysis: Configuration and performance of the data assimilation system. Quart. J. Roy. Meteor. Soc., 137, 553-597, doi:10.1002/qj.828.

Drouard, M., G. Rivière, and P. Arbogast, 2013: The North Atlantic Oscillation response to large-scale atmospheric anomalies in the northeastern Pacific. J. Atmos. Sci., 70, 2854-2874, doi:10.1175/JAS-D-12-0351.1.

— — - and — 2015: The link between the North Pacific climate variability and the North Atlantic Oscillation via 
downstream propagation of synoptic waves. J. Climate, $\mathbf{2 8}$, 3957-3976, doi:10.1175/JCLI-D-14-00552.1.

Eichelberger, S. J., and D. L. Hartmann, 2007: Zonal jet structure and the leading mode of variability. J. Climate, 20, 5149-5163, doi:10.1175/JCLI4279.1.

Feldstein, S. B., 2002: Fundamental mechanisms of PNA growth and decay. Quart. J. Roy. Meteor. Soc., 128, 775-796, doi:10.1256/ 0035900021643683 .

__ 2003: The dynamics of NAO teleconnection pattern growth and decay. Quart. J. Roy. Meteor. Soc., 129, 901-924, doi:10.1256/qj.02.76.

Franzke, C., S. Lee, and S. B. Feldstein, 2004: Is the North Atlantic Oscillation a breaking wave? J. Atmos. Sci., 61, 145-160, doi:10.1175/1520-0469(2004)061<0145:ITNAOA > 2.0.CO;2.

Hartmann, D. L., 2015: Pacific sea surface temperature and the winter of 2014. Geophys. Res. Lett., 42, 1894-1902, doi:10.1002/2015GL063083.

Honda, M., H. Nakamura, J. Ukita, I. Kousaka, and K. Takeuchi, 2001: Interannual seesaw between the Aleutian and Icelandic lows. Part I: Seasonal dependence and life cycle. J. Climate, 14,1029-1042, doi:10.1175/1520-0442(2001)014<1029: ISBTAA $>2.0 . \mathrm{CO} ; 2$.

Horel, J. D., and J. M. Wallace, 1981: Planetary-scale atmospheric phenomena associated with the Southern Oscillation. Mon. Wea. Rev., 109, 813-829, doi:10.1175/1520-0493(1981)109<0813: PSAPAW $>2.0 . \mathrm{CO} ; 2$.

Hoskins, B. J., and D. J. Karoly, 1981: The steady linear response of a spherical atmosphere to thermal and orographic forcing. J. Atmos. Sci., 38, 1179-1196, doi:10.1175/ 1520-0469(1981)038<1179:TSLROA > 2.0.CO;2.

Huntingford, C., and Coauthors, 2014: Potential influences on the United Kingdom's floods of winter 2013/14. Nat. Climate Change, 4, 769-777, doi:10.1038/nclimate2314.

Hurrell, J. W., Y. Kushnir, G. Ottersen, and M. Visbeck, 2003: An overview of the North Atlantic Oscillation. The North Atlantic Oscillation: Climatic Significance and Environmental Impact, Geophys. Monogr., Vol. 134, Amer. Geophys. Union, 1-36.

Lau, N.-C., 1988: Variability of the observed midlatitude storm tracks in relation to low-frequency changes in the circulation pattern. J. Atmos. Sci., 45, 2718-2743, doi:10.1175/ 1520-0469(1988)045<2718:VOTOMS > 2.0.CO;2.

Li, Y., and N.-C. Lau, 2012a: Impact of ENSO on the atmospheric variability over the North Atlantic in late winter-Role of transient eddies. J. Climate, 25, 320-342, doi:10.1175/ JCLI-D-11-00037.1.

— , and — , 2012b: Contributions of downstream eddy development to the teleconnection between ENSO and the atmospheric circulation over the North Atlantic. J. Climate, 25 4993-5010, doi:10.1175/JCLI-D-11-00377.1.

Lorenz, D. J., and D. L. Hartmann, 2003: Eddy-zonal flow feedback in the Northern Hemisphere winter. J. Climate, 16, 1212-1227, doi:10.1175/1520-0442(2003)16<1212:EFFITN>2.0.CO;2.

Martius, O., C. Schwierz, and H. C. Davies, 2007: Breaking waves at the tropopause in the wintertime Northern Hemisphere: Climatological analyses of the orientation and theoretical LC1/2 classification. J. Atmos. Sci., 64, 2576-2592, doi:10.1175/ JAS3977.1.

Matthews, T., C. Murphy, R. L. Wilby, and S. Harrigan, 2014: Stormiest winter on record for Ireland and UK. Nat. Climate Change, 4, 738-740, doi:10.1038/nclimate2336.

Michel, C., and G. Rivière, 2011: The link between Rossby wave breakings and weather regime transitions. J. Atmos. Sci., 68 , 1730-1748, doi:10.1175/2011JAS3635.1.
Nakamura, H., and J. M. Wallace, 1990: Observed changes in baroclinic wave activity during the life cycles of low-frequency circulation anomalies. J. Atmos. Sci., 47, 1100-1116, doi:10.1175/1520-0469(1990)047<1100:OCIBWA > 2.0.CO;2.

, M. Nakamura, and J. L. Anderson, 1997: The role of highand low-frequency dynamics in blocking formation. Mon. Wea. Rev., 125, 2074-2093, doi:10.1175/1520-0493(1997)125<2074: TROHAL $>2.0 . \mathrm{CO} ; 2$.

Orlanski, I., 2005: A new look at the Pacific storm track variability: Sensitivity to tropical SSTs and to upstream seeding. J. Atmos. Sci., 62, 1367-1390, doi:10.1175/JAS3428.1.

Pinto, J. G., M. Reyers, and U. Ulbrich, 2011: The variable link between PNA and NAO in observations and in multi-century CGCM simulations. Climate Dyn., 36, 337-354, doi:10.1007/ s00382-010-0770-x.

Pozo-Vázquez, D., M. J. Esteban-Parra, F. S. Rodrigo, and Y. Castro-Díez, 2001: The association between ENSO and winter atmospheric circulation and temperature in the North Atlantic region. J. Climate, 14, 3408-3420, doi:10.1175/ 1520-0442(2001)014<3408:TABEAW >2.0.CO;2.

Priestley, M. D. K., J. G. Pinto, H. F. Dacre, and L. C. Shaffrey, 2017a: Rossby wave breaking, the upper level jet, and serial clustering of extratropical cyclones in western Europe. Geophys. Res. Lett., 44, 514-521, doi:10.1002/2016GL071277.

$[,-, \ldots$, and $-2017 \mathrm{~b}$ : The role of cyclone clustering during the stormy winter of 2013/2014. Weather, 72, 187-192, doi:10.1002/wea.3025.

Quadrelli, R., and J. M. Wallace, 2004: A simplified linear framework for interpreting patterns of Northern Hemisphere wintertime climate variability. J. Climate, 17, 3728-3744, doi:10.1175/1520-0442(2004)017<3728:ASLFFI>2.0.CO;2.

Rivière, G., and I. Orlanski, 2007: Characteristics of the Atlantic storm-track eddy activity and its relation with the North Atlantic Oscillation. J. Atmos. Sci., 64, 241-266, doi:10.1175/JAS3850.1. , and M. Drouard, 2015a: Dynamics of the northern annular mode at weekly time scales. J. Atmos. Sci., 72, 4569-4590, doi:10.1175/JAS-D-15-0069.1.

_ and _ 2015b: Understanding the contrasting North Atlantic Oscillation anomalies of the winters of 2010 and 2014. Geophys. Res. Lett., 42, 6868-6875, doi:10.1002/2015GL065493.

Simmons, A. J., J. M. Wallace, and G. M. Branstator, 1983: Barotropic wave propagation and instability, and atmospheric teleconnection patterns. J. Atmos. Sci., 40, 1363-1392, doi:10.1175/1520-0469(1983)040<1363:BWPAIA > 2.0.CO;2.

Song, J., C. Li, W. Zhou, and J. Pan, 2009: The linkage between the Pacific-North American teleconnection pattern and the North Atlantic Oscillation. Adv. Atmos. Sci., 26, 229-239, doi:10.1007/s00376-009-0229-3.

Strong, C., and G. Magnusdottir, 2008a: Tropospheric Rossby wave breaking and the NAO/NAM. J. Atmos. Sci., 65, 2861-2876, doi:10.1175/2008JAS2632.1.

— , and 2008b: How Rossby wave breaking over the Pacific forces the North Atlantic Oscillation. Geophys. Res. Lett., 35, L10706, doi:10.1029/2008GL033578.

Takaya, K., and H. Nakamura, 2001: A formulation of a phaseindependent wave-activity flux for stationary and migratory quasigeostrophic eddies on a zonally varying basic flow. J. Atmos. Sci., 58, 608-627, doi:10.1175/1520-0469(2001)058<0608: AFOAPI $>2.0 . \mathrm{CO} ; 2$.

Thompson, D. W. J., and J. M. Wallace, 2000: Annular modes in the extratropical circulation. Part I: Month-to-month variability. J. Climate, 13, 1000-1016, doi:10.1175/1520-0442(2000)013<1000: AMITEC $>2.0 . \mathrm{CO} ;$. 
Trenberth, K., 1986: An assessment of the impact of transient eddies on the zonal flow during a blocking episode using localized Eliassen-Palm flux diagnostics. J. Atmos. Sci., 43, 2070-2087, doi:10.1175/1520-0469(1986)043<2070: AAOTIO $>2.0 . \mathrm{CO} ; 2$.

G. W. Branstator, D. Karoly, A. Kumar, N.-C. Lau, and C. Ropelewski, 1998: Progress during TOGA in understanding and modeling global teleconnections associated with tropical sea surface temperatures. J. Geophys. Res., 103, 14 291-14 324, doi:10.1029/97JC01444.

Uppala, S. M., and Coauthors, 2005: The ERA-40 Re-Analysis. Quart. J. Roy. Meteor. Soc., 131, 2961-3012, doi:10.1256/qj.04.176.

Vallis, G. K., and E. P. Gerber, 2008: Local and hemispheric dynamics of the North Atlantic Oscillation, annular patterns and the zonal index. Dyn. Atmos. Oceans, 44, 184-212, doi:10.1016/ j.dynatmoce.2007.04.003.

P. J. Kushner, and B. A. Cash, 2004: A mechanism and simple dynamical model of the North Atlantic Oscillation and annular modes. J. Atmos. Sci., 61, 264-280, doi:10.1175/ 1520-0469(2004)061<0264:AMASDM>2.0.CO;2.
Wallace, J. M., and D. S. Gutzler, 1981: Teleconnections in the geopotential height field during the Northern Hemisphere winter. Mon. Wea. Rev., 109, 784-812, doi:10.1175/ 1520-0493(1981)109<0784:TITGHF>2.0.CO;2.

_- Y. Zhang, and L. Bajuk, 1996: Interpretation of interdecadal trends in Northern Hemisphere surface air temperature. J. Climate, 9, 249-259, doi:10.1175/1520-0442(1996)009<0249: IOITIN>2.0.CO;2.

Wild, S., D. J. Befort, and G. C. Leckebusch, 2015: Was the extreme storm season in winter 2013/14 over the North Atlantic and the United Kingdom triggered by changes in the West Pacific warm pool? Bull. Amer. Meteor. Soc., 96, S29-S34, doi:10.1175/BAMS-D-15-00118.1.

Woollings, T., B. Hoskins, M. Blackburn, and P. Berrisford, 2008: A new Rossby wave-breaking interpretation of the North Atlantic Oscillation. J. Atmos. Sci., 65, 609-626, doi:10.1175/ 2007JAS2347.1.

_ A. Hannachi, and B. Hoskins, 2010: Variability of the North Atlantic eddy-driven jet stream. Quart. J. Roy. Meteor. Soc., 136, 856-868, doi:10.1002/qj.625. 